\title{
Competing behavior and observing responses
}

STEPHEN B. KENDALL

UNIVERSITY OF ALABAMA

\begin{abstract}
Two pigeons were trained to make observing responses in a mixed FR FR schedule. Two responses to the observing key produced stimuli correlated with one or the other of the FRs. One of the FRs was then lowered to two to strengthen food behavior immediately after reinforcement. One of the Ss showed a sizable drop in observing response output. The other pigeon's observing response output dropped as the size of the larger FR was increased.
\end{abstract}

Problem

In an observing response experiment the $\mathrm{S}$ is placed on a mixed schedule of reinforcement. No exteroceptive stimulus signals the change from one schedule component to another. The $\mathrm{S}$, however, is provided the opportunity, via the observing response, to present himself with exteroceptive stimuli which are correlated with the different schedule components. By making the observing response the $\mathrm{S}$ may convert the mixed schedule into a multiple schedule.

A previous study (Kendall, in press) demonstrated that when a mixed FI FR schedule is employed, the $S$ gives a modal frequency of one observing response per schedule component, even when the duration of the stimuli is considerably shorter than the duration of the FI or FR component. In addition, it was found that the observing response was emitted soon after reinforcement, before responding for food began.

The results were interpreted in a competing response framework originally proposed by Kelleher, Fry, \& Cook (1962). Assuming that a pause follows reinforcement, observing behavior is able to successfully compete with food behavior. When a stimulus is produced, food behavior is initiated and competes with further observing behavior. The present experiment examines observing response output when conditions are arranged such that food behavior is strong immediately after reinforcement。

\section{Method}

The Ss were two White King pigeons, run at $80 \%$ of free-feeding weight. Prior to this experiment, they had served in another observing response experiment with two FR schedules where the size of the lower FR varied between 10 and 30 with the upper FR held at 50 (Kendall, 1965).

The apparatus has been described elsewhere (Kendall, 1964). It consisted of a two key pigeon chamber and associated programming equipment. Responses and reinforcements were recorded on a cumulative recorder and discriminative stimuli and reinforcements were recorded on an event recorder. The pigeon chamber was housed in a sound attenuating chamber, in a separate room from the programming equipment.
Immediately following the experiment mentioned above, the pigeons were placed on the following contingencies. P-4A was put on a mixed FR75 FR20 schedule on the food (right) key. The observing contingency was in effect on the observing (left) key. Two pecks at the observing key (both pecks will be referred to as the "observing response'") produced one of two lights on the food key, depending on which FR was present. If FR75 was in effect, an observing response produced a blue light; if FR20 was in effect, the observing response produced a red light. The stimuli were presented for $30 \mathrm{sec}$. or until a reinforcement occurred, which ever was first. The programmer which selected the FR moved forward only at reinforcement. The sequence of FRs was roughly random, except that no runs of more than three of the same FRs were allowed.

When stability of FR behavior and observing behavior had been achieved, the FR20 was lowered to FR2. There was no change in the sequence of FRs or in the observing response requirement. The $\mathrm{S}$ was again run until he was stable. After the completion of these two phases, the entire procedure was replicated with the stimulus duration set at $5 \mathrm{sec}$. Stability was achieved in all phases of the experiment within 30 sessions. A session lasted until the bird had collected between 70-100 reinforcements, depending on his weight.

The procedure for P-4B was the same with these exceptions: (a) he was initially placed on a mixed FR50 FR10 schedule on the food key, and (b) instead of replicating the experiment with a different stimulus duration, the value of the larger of the FRs was increased, first to 75 and then to 100 . The bird was run until he had collected 50-70 reinforcements, depending on his weight.

\section{Results}

The results of this experiment are presented in terms of an "observing ratio." Previous work, mentioned above, indicated that usually, only one observing response is emitted in any given schedule component. In other words, there is about one observing response per reinforcement when observing responses are being maintained. The observing ratio is, then, the number of observing responses divided by the number of reinforcements $\left(S^{D} / S^{R}\right)$. The symbol " $S^{D}$ " is used since the number of observing responses is, by definition, equal to the number of times the stimuli are presented. It should be noted that in many instances in the present experiment the observing ratio had an upper limit of one, since the ratios could be completed within 30 sec. All data presented represent means of the last four days under a given condition.

The results for the entire experiment for $\mathrm{P}-4 \mathrm{~A}$ 


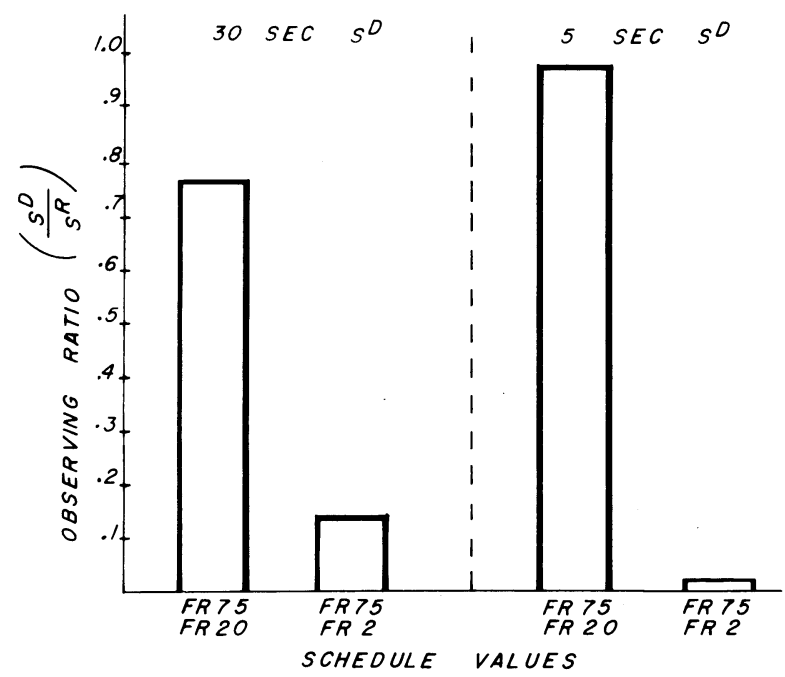

Fig. 1. Observing ratios for P-4A under FR75 FR20 and FR75 FR2 schedules. Two values are presented for each schedule, one with a 30 sec. $S^{D}$ and the other with a 5 sec. $S^{D}$ (see text for explanation).

are presented in Fig. 1. The results for P-4B are presented in Fig. 2. For P-4A the observing ratio drops from about .77 to about .15 with the change in the value of the lower FR under the $30 \mathrm{sec}$. stimulus condition. A more dramatic change is seen in the replication with the $5 \mathrm{sec}$. stimulus. The observing ratio does not exceed 1.0 with the 5 sec. stimulus condition even though, under the FR75 FR20 schedule, the bird did not usually complete either ratio within $5 \mathrm{sec}$.

The data for $\mathrm{P}-4 \mathrm{~B}$ do not show a very impressive decline in observing response output when the lower FR is changed to FR2. Increasing the value of the larger FR, however, produces further declines in observing response output. One striking feature of

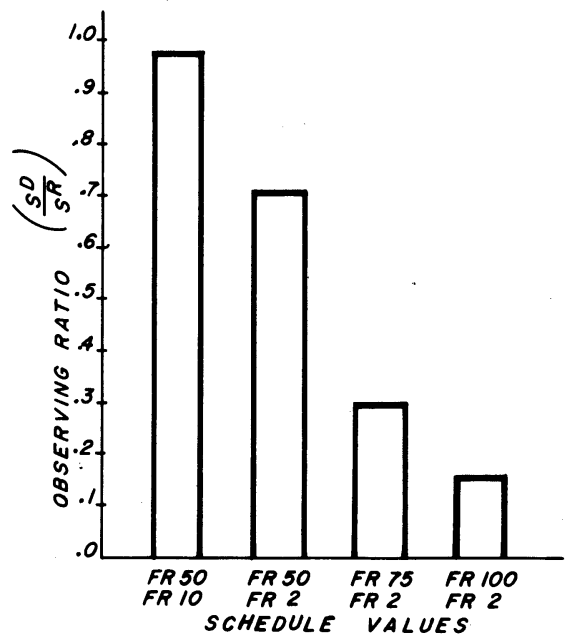

Fig. 2. Observing ratios for $P-4 B$ under four different food schedules (see text for explanation). this bird's behavior was that a short run of responses occurred on the food key immediately after reinforcement. If the current schedule was FR2 the S was reinforced. If, however, the larger FR was present a pause followed the short burst of responses. During this pause an observing response was sometimes made. The probability of this observing response depended on the value of the larger FR. This was not noted in P-4A. This behavior was first noted in P-4B when the schedule was FR75 FR2. A check of the records indicated that about $90 \%$ of all observing responses were made following a burst of responses on the food key. When this sequence of events occurred the $\mathrm{S}$ was certain to receive the stimulus correlated with the larger FR.

\section{Discussion}

The results of this experiment fortify at least a part of the competing response hypothesis. When conditions are arranged so that food behavior is quite strong immediately after reinforcement (when the lower FR is FR2) food behavior is prepotent over observing behavior. Not supported by this experiment is the idea that when a stimulus has terminated, it is not observed again because of the competition of food behavior and observing behavior. The results may be interpreted only with respect to competition between food and observing behavior immediately after reinforcement.

The results from $\mathrm{P}-4 \mathrm{~B}$ are particularly interesting. Consider a mixed FR FR schedule with no observing response. Depending on the absolute size of the ratios and the amount of difference between them, the following may occur. After a reinforcement, the $\mathrm{S}$ begins responding. If the smaller FR is present, he will be reinforced when the requisite number of responses is emitted. If, however, the larger FR is present a pause may follow a burst of responses about equal in number to the size of the smaller ratio (Ferster \& Skinner, 1957). During this pause, other behavior can successfully compete with food behavior. In the present experiment P-4A was likely to emit an observing response during this pause. Immediately after reinforcement, however, food behavior was prepotent.

\section{References}

Kelleher, R. T., Riddle, W. C., \& Cook, L. Observing responses in pigeons. J. exp. Anal. Behav., 1962, 5, 3-13.

Kendall, S. B. Fixed interval behavior in mixed and multiple schedules with alternating fixed interval-fixed ratio components. Psychon. Sci., 1964, 1, 165-166.

Kendall, S. B. The distribution of observing responses in a mixed FI-FR schedule. J. exp. Anal. Behav., in press.

Kendall, S. B. An observing response analysis of fixed ratio discrimination. Psychon. Sci., 1965, 3, 281-282. 